Article

\title{
Assembly and Redox-Rich Hydride Chemistry of an Asymmetric $\mathrm{Mo}_{2} \mathrm{~S}_{2}$ Platform
}

\author{
Alex McSkimming, Jordan W. Taylor and W. Hill Harman *D \\ Department of Chemistry, University of California, Riverside, California, CA 92521, USA; \\ alexander.mcskimming@ucr.edu (A.M.); jtay1015@ucr.edu (J.W.T.) \\ * Correspondence: hill.harman@ucr.edu; Tel.: +1-(951)-827-3786
}

Academic Editor: Derek J. McPhee

Received: 29 May 2020; Accepted: 2 July 2020; Published: 7 July 2020

\begin{abstract}
Although molybdenum sulfide materials show promise as electrocatalysts for proton reduction, the hydrido species proposed as intermediates remain poorly characterized. We report herein the synthesis, reactions and spectroscopic properties of a molybdenum-hydride complex featuring an asymmetric $\mathrm{Mo}_{2} \mathrm{~S}_{2}$ core. This molecule displays rich redox chemistry with electrochemical couples at $E_{\frac{1}{2}}=-0.45,-0.78$ and $-1.99 \mathrm{~V}$ vs. $\mathrm{Fc}_{\mathrm{Fc}} \mathrm{Fc}^{+}$. The corresponding hydrido-complexes for all three redox levels were isolated and characterized crystallographically. Through an analysis of solid-state bond metrics and DFT calculations, we show that the electron-transfer processes for the two more positive couples are centered predominantly on the pyridinediimine supporting ligand, whereas for the most negative couple electron-transfer is mostly Mo-localized.
\end{abstract}

Keywords: molybdenum sulfides; hydrides; redox-active ligands

\section{Introduction}

Efficient electro or photocatalytic reduction of protons to produce $\mathrm{H}_{2}$ gas remains an important challenge [1-5]. Not only is $\mathrm{H}_{2}$ a potential clean fuel, but is by far the most used chemical reductant [6]. $\mathrm{H}_{2}$ is typically produced industrially by the steam reforming of methane [7]. Although this process utilizes a nonrenewable hydrocarbon feedstock and generates large volumes of greenhouse gases, the low efficiency of current water splitting technologies makes steam reforming by far the most economical process [5]. As a result, a tremendous amount of research has revolved around discovery and optimization of new materials for the hydrogen evolution reaction (HER) [1-5]. Some of the most promising heterogeneous catalysts for this reaction are molybdenum sulfides $\left(\mathrm{MoS}_{x}\right)$, which exhibit comparable overpotentials and current densities to $\mathrm{Pd} / \mathrm{Pt}$ electrodes but are significantly cheaper [8-10]. Although the mechanism of proton reduction by $\mathrm{MoS}_{x}$ materials is not fully understood, calculations implicate molybdenum-hydrido intermediates that are protonated to give $\mathrm{H}_{2}$ [11-14]. A number of molecular analogues for the surface interface of $\mathrm{MoS}_{x}$ materials have been shown to be active HER catalysts, although Mo-H intermediates, if they are formed, have not been well-characterized [15-22]. Indeed, molecular Mo-H complexes featuring sulfur-donor ligands, particularly sulfides, are uncommon [23-37]. Consequently, we have been interested in preparing molybdenum-hydride complexes with sulfide ligands and studying their chemistry and spectroscopy. We report, herein, preparation of hydrido complexes featuring an $\mathrm{Mo}_{2} \mathrm{~S}_{2}$ core and an examination of their redox properties, reactions and electronic structure. 


\section{Results}

\subsection{Synthesis of Complexes}

In approaching this chemistry, we targeted $\mathrm{Mo}_{2} \mathrm{~S}_{2}$ complexes for which each Mo site would reside in a distinct coordination environment. We hoped this would facilitate selective installation of a hydrido ligand at a single Mo, and so greatly simplify reactivity and spectroscopic studies. $\mathrm{The}^{\mathrm{M}} \mathrm{Mo}_{2} \mathrm{~S}_{2}$ motif is common in the literature; however, all such complexes are approximately symmetric and, typically, coordinatively saturated [38].

The assembly of an asymmetric $\mathrm{Mo}_{2} \mathrm{~S}_{2}$ core and selective installation of a single hydride ligand are depicted in Scheme 1. First, reaction of the formally $\mathrm{Mo}^{3+}$ complex (PDI) $\mathrm{MoCl}_{3}$ [39] $\left(\mathrm{PDI}=\left(1,1^{\prime}\right.\right.$-(pyridine-2,6-diyl)bis(N-(2,6-diisopropylphenyl)ethan-1-imine) $)$ with a stoichiometric amount of $\mathrm{K}\left(\mathrm{C}_{10} \mathrm{H}_{8}\right)(\mathrm{THF})_{0.5}$ in tetrahydrofuran (THF) gave the one-electron reduced complex trans-(PDI) $\mathrm{MoCl}_{2}$ (THF) (1 in Scheme 1) as a dark-green crystalline solid in 56\% yield. Complex 1 was paramagnetic with an effective magnetic moment of $2.7 \pm 0.2 \mu \mathrm{B}$ in solution, consistent with an $S=1$ ground state. Reaction of 1 with the dihydrosulfido complex $\mathrm{Cp}_{2} \mathrm{Mo}(\mathrm{SH})_{2}[40]$ gave the mono-hydrosulfido-bridged, trans-(PDI) $\mathrm{MoCl}_{2}(\mu-\mathrm{SH}) \mathrm{Mo}(\mathrm{SH}) \mathrm{Cp}_{2}$ (2 in Scheme 1). This complex degraded rapidly in solution and so proved difficult to characterize. In spite of this, bond connectivity was assigned from a poor-quality single-crystal X-ray diffraction (XRD) study (Figure S1B). Deprotonation of 2 using 2 equivalents of 1,8-diazabicyclo [5.4.0]undec-7-ene (DBU) gave the sulfido-bridged complex (PDI)Mo( $\mu-S){ }_{2} \mathrm{Mo}\left(\eta^{5}-\mathrm{Cp}\right)\left(\eta^{1}-\mathrm{Cp}\right)(3$ in Scheme 1$)$ as a dark-red solid. Strikingly, one $\mathrm{Cp}$ ligand switched from $\eta^{5}$ to $\eta^{1}$ coordination mode upon deprotonation. Although this complex could not be obtained in analytically pure form, it proved sufficiently pure to explore its utility as a precursor to Mo-H complexes.

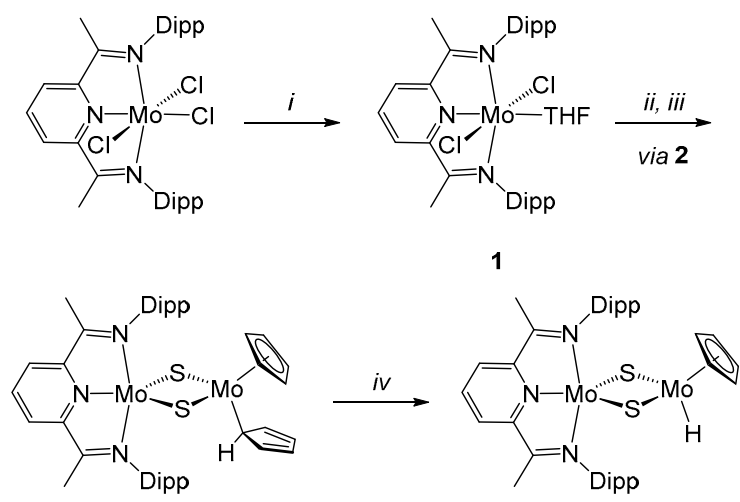

3

Scheme 1. Synthesis of complexes 1-4. Reagents and conditions: i. $\mathrm{K}\left(\mathrm{C}_{10} \mathrm{H}_{8}\right), \mathrm{THF}(56 \%)$; ii. $\mathrm{Cp}_{2} \mathrm{Mo}(\mathrm{SH})_{2}$; iii. 2 eq. $\mathrm{DBU}$ (70\% over 2 steps); iv. xs. $\mathrm{NaBH}_{4}(60 \%)$.

Initially, we wondered whether protonolysis of 3 would yield $\mathrm{CpH}$ and the coordinately unsaturated cation, ((PDI)Mo $\left.(\mu-S){ }_{2} \mathrm{Mo}\left(\eta^{5}-\mathrm{Cp}\right)\right)^{+}$, which might then be reduced to give the hydrido complex (PDI)Mo $(\mu-S)_{2} \mathrm{Mo}\left(\eta^{5}-\mathrm{Cp}\right)(\mathrm{H})(4$ in Scheme 1). Unfortunately, attempted protonation of 3 using a variety of both weak and strong acids (e.g., (2,6-lutidinium) salts, $\mathrm{H}\left(\mathrm{OEt}_{2}\right)_{2}\left[\mathrm{BAr}^{\mathrm{F}}{ }_{4}\right]\left(\mathrm{BAr}^{\mathrm{F}}{ }_{4}=\right.$ tetrakis(3,5-bistrifluoromethyl phenyl borate)) gave only complex mixtures. In further studies, however, we were surprised to find that reaction of 3 with strong one electron reductants such as $\mathrm{KC}_{8}$ gave mixtures displaying resonances $<\delta-5$ in crude ${ }^{1} \mathrm{H}-\mathrm{NMR}$ spectra, suggesting the formation of Mo-hydrido species. In an effort to isolate one such complex, 3 was reacted with an excess of $\mathrm{Na}\left[\mathrm{BH}_{4}\right]$ in THF to, fortuitously, produce the diamagnetic, yellow-brown hydrido complex 4 in $60 \%$ isolated yield. The corresponding deuterido complex 4-D was synthesized analogously using $\mathrm{Na}\left[\mathrm{BD}_{4}\right](95 \%-\mathrm{D})$. The ${ }^{1} \mathrm{H}-\mathrm{NMR}$ spectrum of 4 showed a signal of relative integration 1 at $\delta-12.58$, consistent with a metal-hydride functionality (see Figure S2A). As expected, the intensity of this peak was diminished by ca. $95 \%$ in the ${ }^{1} \mathrm{H}-\mathrm{NMR}$ spectrum of 4 -D. 
A $1 \mathrm{D}-{ }^{1} \mathrm{H}-{ }^{1} \mathrm{H}$ NOESY experiment with selective irradiation of the hydride resonance showed a strong cross-peak to the $\mathrm{C}_{5} \mathrm{H}_{5}$ signal, indicating that the hydrido ligand bound the $\mathrm{Cp}$-substituted Mo (Figure S2B). Positive-mode liquid injected field desorption (LIFDI) mass spectrometry showed a peak at $\mathrm{m} / \mathrm{z}$ 807.1475 (calcd. 807.1471) for the molecular ion, [4] $]^{+}$. As is not uncommon [41] the FT-IR spectrum of 4 contained no bands that could be unambiguously assigned to an Mo-H stretch (nor could any be identified in (Fourier transform infrared) FT-IR spectra of its reduced/oxidized congeners, vide infra; see Figures S3 and S4). Further, indirect evidence for the existence of a Mo-H moiety in 4 was provided by its rapid reaction with $\mathrm{CDCl}_{3}$ to produce $\mathrm{CDHCl}_{2}$ (see Figure S5) [42].

Given the potential relationship between Mo-H species and heterogenous $\mathrm{MoS}_{x}$ HER catalysts (see Section 1), we were particularly interested to explore the redox chemistry of 4 . The cyclic voltammogram (CV) recorded for 4 in $0.1 \mathrm{M} \mathrm{Na}\left[\mathrm{BAr}^{\mathrm{F}}\right.$ ] in THF is shown in Figure 1. On the CV timescale, complex 4 displayed rich redox chemistry, with reversible processes at $E_{\frac{1}{2}}=-1.99,-0.78$ and $-0.45 \mathrm{~V}$ vs. $\mathrm{Fc} / \mathrm{Fc}^{+}$(open circuit potential $\sim 1.2 \mathrm{~V}$; see Figure $\mathrm{S} 6$ for Randles-Sevcik plots). These were assigned to the $4 /[4]^{-}, 4 /[4]^{+}$and $[4]^{+} /[4]^{2+}$ couples, respectively. Given the anticipated extent of PDI-Mo orbital mixing (see also Section 2.4), [43] we expected that it would be problematic to assign these couples to localized electron-transfer processes from CV data alone. We wondered, then, if [4] ${ }^{-}$, $[4]^{+}$and/or $[4]^{2+}$ could be isolated on a preparative scale and their properties examined to shed further light on the redox chemistry of these systems.

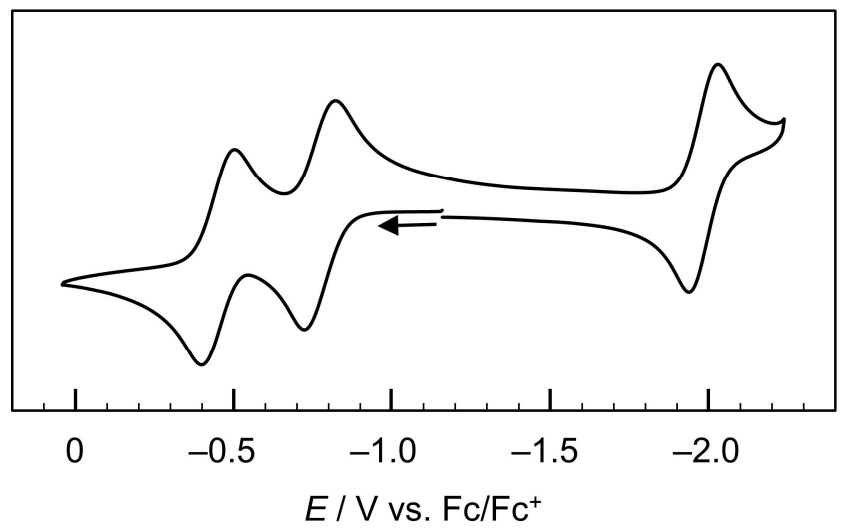

Figure 1. Cyclic voltammogram recorded for complex 4. Conditions: $1 \mathrm{mM}$ in THF-Na[BAr $\left.{ }_{4}{ }_{4}\right]$ at $100 \mathrm{mV} \mathrm{s}^{-1}$.

The redox and protonation chemistry of 4 is summarized in Scheme 2. First, reduction of 4 using metallic $\mathrm{Na}$ in diethyl ether followed by encapsulation of $\mathrm{Na}^{+}$by [2.2.2]Cryptand (crypt-2.2.2) gave [4][Na(crypt-2.2.2)] as a brown, crystalline solid in $84 \%$ yield. Second, the dark-blue one-electron oxidized complex [4][BAr ${ }_{4}$ ] was prepared from 4 in $70 \%$ yield by addition of 1 equivalent of either $\left[\mathrm{Ph}_{3} \mathrm{C}\right]\left[\mathrm{BAr}_{4}{ }_{4}\right]$ or $[\mathrm{Fc}]\left[\mathrm{BAr}_{4}{ }_{4}\right]$. In the case of the former reagent, peaks for Gomberg's dimer (the one-electron reduction product of $\mathrm{Ph}_{3} \mathrm{C}^{+}$) were observed in the ${ }^{1} \mathrm{H}-\mathrm{NMR}$ spectrum of the crude reaction mixture. In the absence of air and moisture, both the one-electron oxidized and reduced clusters were stable for prolonged periods ( $>1$ week) at room temperature (RT) in both the solid state and in solution. Both had $S=1 / 2$ ground-states as indicated by their electron paramagnetic resonance (EPR) spectra (see Section 2.2) and solution state magnetic moments of $\sim 2 \mu \mathrm{B}$.

In contrast to the syntheses of $[4]^{+/-}$, isolation of the two-electron oxidized complex, $[4]^{2+}$, proved more difficult. For example, addition of 2 equivalents of $[\mathrm{Fc}]\left[\mathrm{BAr}_{4}\right.$ ] to complex 4 in a variety of solvents gave intractable mixtures; the crude samples showed at least 3 diamagnetic Mo-H species. We speculated that the presumably highly electrophilic dication $[4]^{2+}$ could be stabilized by incorporation of more coordinating anion(s). Accordingly, addition of 2 equivalents of [Fc][OTf] to 4 in THF cleanly generated the 2-electron oxidized, diamagnetic [(PDI)Mo(OTf $\left.)(\mu-S){ }_{2} \mathrm{Mo}\left(\eta^{5}-\mathrm{Cp}\right)(\mathrm{H})\right][\mathrm{OTf}]$ ([4-OTf][OTf]) as a red-brown crystalline solid in $84 \%$ yield. In the solid state one triflato group 
bound the PDI-ligated Mo with the other remaining outer sphere. In contrast to putative $[4]\left[\mathrm{BAr}^{\mathrm{F}}{ }_{4}\right]_{2}$, ([4-OTf][OTf]) was indefinitely thermally stable in the solid state and decomposed only slowly over days in acetone solution at room temperature (RT). The ${ }^{1} \mathrm{H}-\mathrm{NMR}$ spectrum of [4-OTf][OTf] showed a broad signal at $\delta-12.02$ of relative integration 1 for the hydrido atom. Positive-mode LIFDI mass spectrometry performed on [4-(OTf)]+ showed a peak at $m / z 956.1039$ for the molecular ion [4-OTf]+ (calcd., 956.0991).

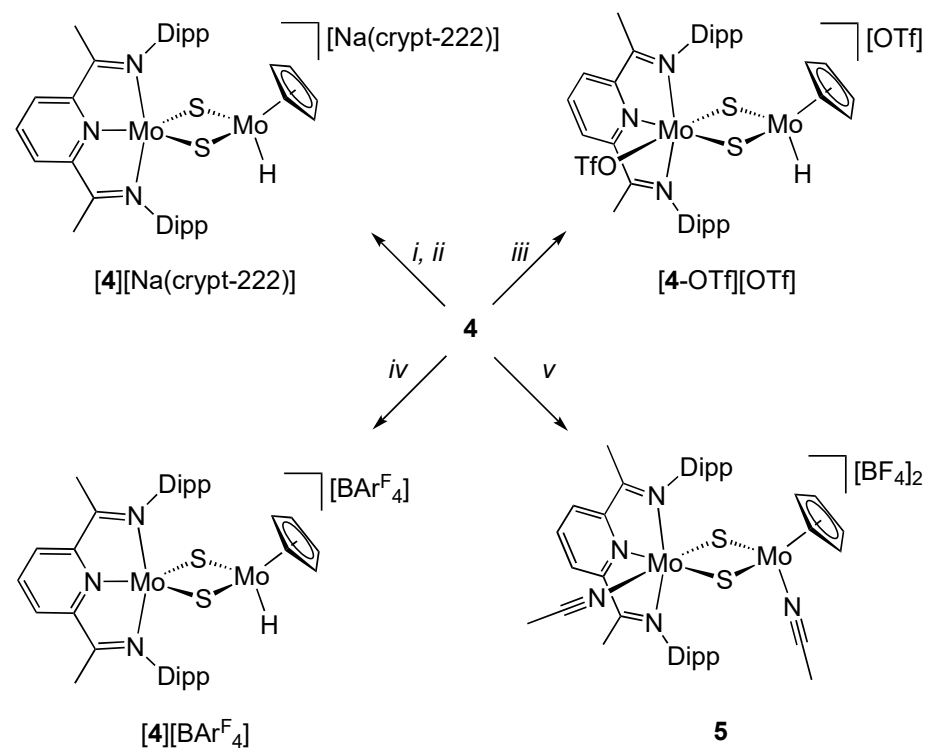

Scheme 2. Redox and protonation chemistry of complex 4. Reagents and conditions: i. xs. $\mathrm{Na}^{0}$; ii. 1 Equation. [2.2.2]-Cryptand (crypt-222) (84\% over 2 steps); iii. 2 Equation. Fc[OTf] (84\%); iv. [Ph $\left.{ }_{3} \mathrm{C}\right]\left[\mathrm{BAr}{ }_{4}\right]$ (70\%); v. xs. $\left[\mathrm{Ph}_{2} \mathrm{NH}_{2}\right]\left[\mathrm{BF}_{4}\right](90 \%)$.

In addition to its redox chemistry, we were also interested in examining the reaction of 4 with proton sources. Addition of excess $\left[\mathrm{Ph}_{2} \mathrm{NH}_{2}\right]\left[\mathrm{BF}_{4}\right]$ to a suspension of 4 in MeCN resulted in rapid evolution of $\mathrm{H}_{2}$ gas (by ${ }^{1} \mathrm{H}-\mathrm{NMR}$ spectroscopy) and formation of an intensely purple solution. From this mixture the dark-purple dication $\left[(\mathrm{PDI}) \mathrm{Mo}(\mathrm{MeCN})(\mu-\mathrm{S})_{2} \mathrm{Mo}\left(\eta^{5-} \mathrm{Cp}\right)(\mathrm{MeCN})\right]\left[\mathrm{BF}_{4}\right]_{2}(5)$ was isolated in $90 \%$ yield. As with [4] $]^{+/-}$, complex 5 had an $S=1 / 2$ ground-state as shown by EPR spectroscopy (see Section 2.2) and a solution state magnetic moment of $2.0 \pm 0.1 \mu_{\mathrm{B}}$. In contrast to the neutral 4, reaction of the anionic complex $[4]^{-}$with $\left[\mathrm{Ph}_{2} \mathrm{NH}_{2}\right]\left[\mathrm{BF}_{4}\right]$ gave a complex mixture of products. Repeated recrystallizations ultimately separated a small quantity of red-orange crystals, which were identified by XRD as a $\mathrm{Mo}_{4} \mathrm{~S}_{4}$ cubane (6), which featured a partially hydrogenated PDI ligand (see Figure S1E). The variable protic stability of the $\mathrm{Mo}_{2} \mathrm{~S}_{2}$ core, when in different formal redox states, will be an important consideration when optimizing these types of systems as catalysts for the HER.

\subsection{EPR Spectroscopy}

As expected, the paramagnetic, half-integer spin $[4]^{+/-}$and 5 were all EPR-active. Continuous wave $(\mathrm{CW}) \mathrm{X}$-band EPR spectra recorded on dilute, frozen glasses of these complexes at $100 \mathrm{~K}$ showed complex envelopes of peaks with extensive hyperfine structure centered at $\mathrm{g} \approx 2$, indicative of an $S=1 / 2$ ground state for all three species (Figure 2). The most likely origins of these hyperfine interactions are coupling to a combination of ${ }^{95 / 97} \mathrm{Mo},{ }^{14} \mathrm{~N}$ in the PDI/MeCN ligand(s) and/or the hydrido ${ }^{1} \mathrm{H}$ $\left(\right.$ for $[4]^{+/-}$). The latter could be ruled out as the EPR spectra of $[4]^{+/-}$were indistinguishable from those recorded for $[4-\mathrm{D}]^{+/-}$. The EPR spectrum of the cation $[4]^{+}$(Figure 2A) was sufficiently resolved to be well-simulated by modelling hyperfine coupling to only natural abundance ${ }^{95 / 97} \mathrm{Mo}(\mathrm{A}=110$, 35, $180 \mathrm{MHz}$ ). For [4] ${ }^{-}$and 5 (Figure 2B,C), however, conclusive simulations could not be obtained without overparameterization. 


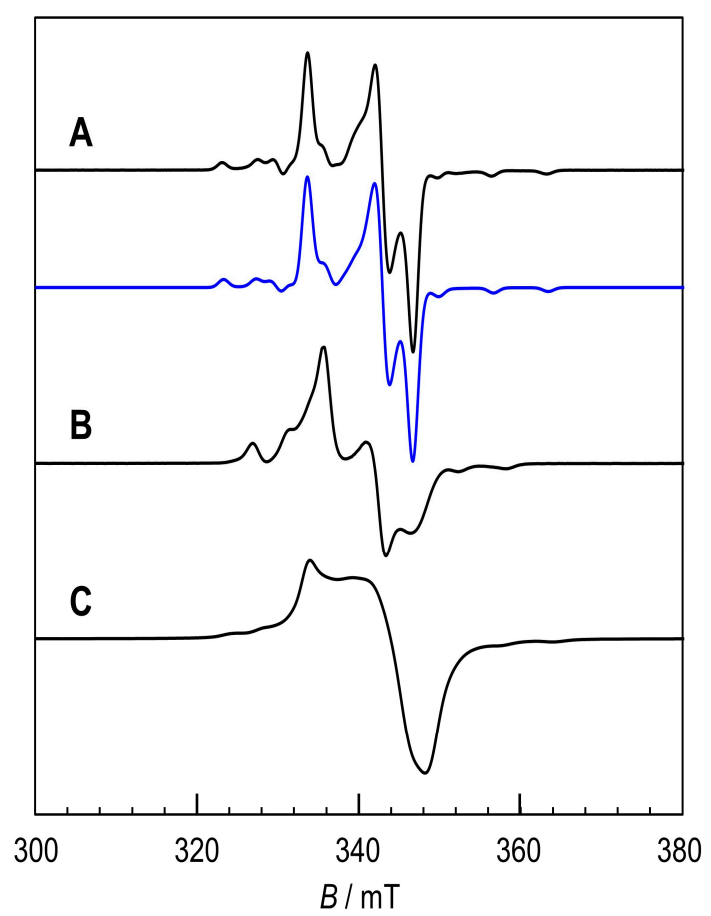

Figure 2. Continuous wave electron paramagnetic resonance (CW EPR) spectra recorded for $[4]^{+}(\mathrm{A})$, $[4]^{-}(\mathrm{B})$ and $5(\mathrm{C})$ at $100 \mathrm{~K}, 9.32 \mathrm{GHz}$ and $0.02 \mathrm{~mW}$ power. Experimental spectra are shown in black, simulations in blue. Conditions and (simulated) parameters: (A) 2-MeTHF; $g=2.00,1.94$, $1.92\left(g_{\text {iso }}=1.95\right) ; \mathrm{H}$ strain $=29,36,31 \mathrm{MHz} ; \mathrm{lw}=1 \mathrm{mT}$; (B) DMAc-2MeTHF (1:1); $g_{\text {iso }} \sim 1.95$ (C) MeCN-toluene (1:1); $g_{\text {iso }} \sim 1.95$.

\subsection{Crystallography}

Single crystal XRD studies were performed on the four hydride complexes and also complexes $\mathbf{1}$, 3 and 5 . Views from the crystal structures of the hydride complexes are presented in Figure 3; structures for 1, 3, $\mathbf{5}$ and connectivity assignments for $\mathbf{2}$ and $\mathbf{6}$ are shown in Figure S1. Selected experimental bond lengths and angles are summarized in Table 1. Electron density for the hydrido ligands was located in the difference map for all of the hydride complexes.

Table 1. Selected structural metrics for 4 and its oxidized and reduced congeners.

\begin{tabular}{ccccccccc}
\hline & (Cp)Mo-S & (PDI)Mo-S & Mo-Mo & $\mathbf{N}_{\mathbf{i m}} \mathbf{M o}$ & $\mathbf{N}_{\mathbf{p y}} \mathbf{M o}$ & $\mathbf{N}_{\mathbf{i m}}=\mathbf{C}_{\mathbf{i m}}$ & $\mathbf{C}_{\mathbf{i m}}-\mathbf{C}_{\mathbf{p y}}$ & $\angle \mathbf{M o S M o}$ \\
\hline [4-OTf $^{+}$ & $2.261(2)$ & $2.2598(5)$ & $2.770(1)$ & $2.172(1)$ & $2.173(1)$ & $1.297(2)$ & $1.473(2)$ & $75.59(4)$ \\
& $2.269(2)$ & $2.2967(6)$ & & $2.173(1)$ & & $1.298(2)$ & $1.467(2)$ & $74.71(4)$ \\
{$[4]^{+}$} & $2.2790(4)$ & $2.2433(5)$ & $2.7832(4)$ & $2.128(2)$ & $2.126(1)$ & $1.318(2)$ & $1.440(3)$ & $75.97(2)$ \\
& $2.2332(6)$ & $2.2921(5)$ & & $2.093(2)$ & & $1.345(2)$ & $1.441(2)$ & $75.90(2)$ \\
4 & $2.2419(9)$ & $2.2912(7)$ & $2.8237(6)$ & $2.103(2)$ & $2.072(2)$ & $1.352(3)$ & $1.406(3)$ & $77.05(2)$ \\
& $2.2964(7)$ & $2.2525(9)$ & & $2.111(2)$ & & $1.344(2)$ & $1.412(3)$ & $76.72(2)$ \\
{$[4]^{-}$} & $2.291(1)$ & $2.299(1)$ & $2.8255(7)$ & $2.132(2)$ & $2.028(2)$ & $1.364(3)$ & $1.407(3)$ & $75.99(4)$ \\
& $2.271(1)$ & $2.307(1)$ & & $2.162(2)$ & & $1.355(3)$ & $1.403(3)$ & $76.22(3)$ \\
\hline
\end{tabular}




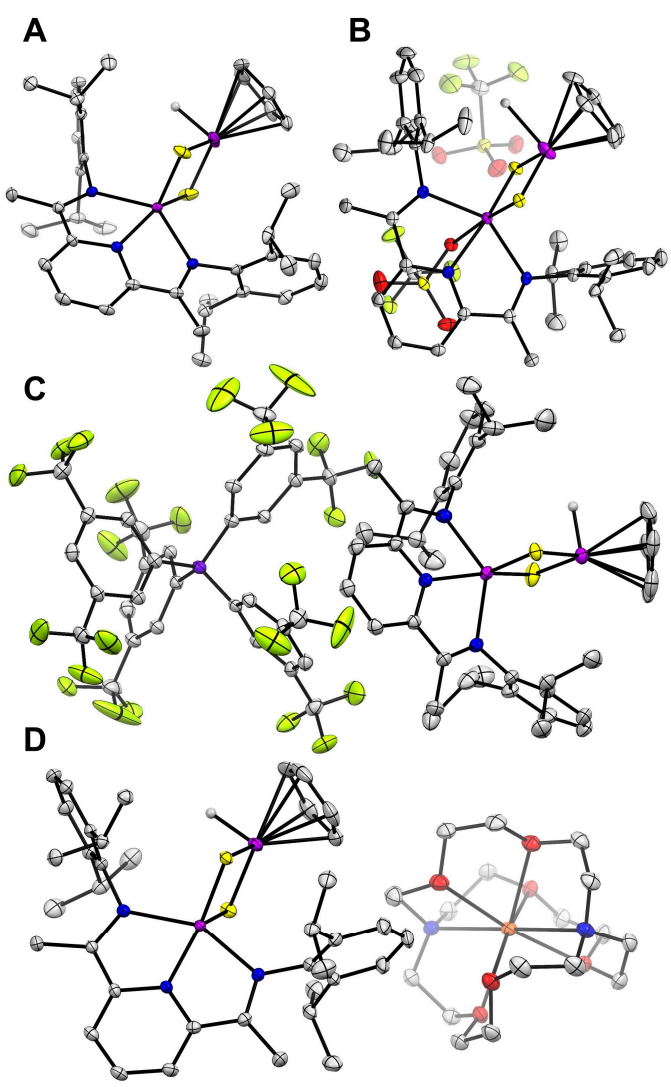

Figure 3. Thermal ellipsoid plots (50\%) of (A) 4, (B) [4-OTf][OTf] (B), (C) [4][BAr $\left.{ }_{4}{ }_{4}\right]$ and (D) [4][Na-crypt222]. Magenta, yellow, blue, orange, green and grey ellipsoids represent Mo, S, N, Na, $\mathrm{F}$ and $\mathrm{C}$, respectively. Hydrogen atoms not bound to Mo and solvent molecules are omitted for clarity.

PDIs are prototypical redox active ligands, and electron transfer processes for their complexes are frequently PDI-localized $[44,45]$. The extent to which the $C=N_{i m}(i m=$ imine $)$ and $C_{p y}-C_{i m}$ (py = pyridine) bonds lengthen and shorten, respectively, has proved a useful proxy for a qualitative assessment of the extent to which the PDI has been reduced. [46] PDI ligands are known to be able to accept up to 3 electrons to give the (formal) radical trianion, [PDI $]^{3-}[46]$. With this in mind, inspection of the structural data revealed several key trends. First, the average Mo-S bond distances changed only slightly $(\leq 0.01 \AA)$ between $[4-\mathrm{OTf}]^{+},[4]^{+}$and 4 . In contrast, for the anion $[4]^{-}$, the Mo-S bonds at both Mo sites were longer than for the three more oxidized complexes by $\sim 0.03 \AA$. In addition, upon one-electron reduction of 4 to $[4]^{-}$, the $\mathrm{Mo}-\mathrm{N}_{\mathrm{im}}$ and $\mathrm{Mo}-\mathrm{N}_{\mathrm{py}}$ distances sharply increased and decreased, respectively, by $\sim 0.05 \AA$. Second, the $\mathrm{C}=\mathrm{N}_{\mathrm{im}}$ and $\mathrm{C}_{\mathrm{py}}-\mathrm{C}_{\mathrm{im}}$ bonds expanded and contracted, respectively, on moving from [4-OTf $]^{+}$to $[4]^{+}$to 4 by roughly $0.03 \AA$ per oxidation level. In contrast, metrics within the PDI system changed little between 4 and [4] $]^{-}$; indeed, the $C_{p y}-C_{i m}$ bonds lengthened very slightly. Overall, we hypothesise that upon sequential reduction of $[4-\mathrm{OTf}]^{+}$, the first two electrons are placed in MOs of mostly PDI- $\pi^{*}$ character, and the third into an MO of mostly metal character. This idea was explored further using computational methods (Section 2.4).

\subsection{Density Functional Theory Calculations}

In order to more thoroughly understand the electronic structure of these molecules, we turned to density functional theory (DFT). All calculations were performed on truncated structures obtained from XRD coordinates with the diisopropylphenyl (Dipp) and methyl groups of the PDI ligand replaced with protons. The unrestricted Kohn-Sham HOMOs and HOMO-1s calculated for the four hydride complexes are shown in Figure 4. The calculated orbital picture agrees well with the electronic structure assignments suggested by the solid state bond metrics. First, for [4-OTf] $]^{+}$the doubly 
occupied $\mathrm{HOMO}$ is of predominantly $\mathrm{Mo}(\mathrm{d})$-character and is essentially nonbonding with respect to the entire $\sigma$ framework. The low-lying PDI- $\pi^{*} \mathrm{MO}$ (not shown) remains unfilled. For complex $[4]^{+}$, the singly-occupied HOMO is strongly localized (65\%) on the PDI ligand with some $\pi^{*}$-Mo(d) mixing. The orbital picture upon one-electron reduction to $[4]^{-}$remains similar with the HOMO now doubly-occupied. In contrast, the singly-occupied HOMO for the anion [4] $]^{-}$is of predominantly (PDI)Mo(d)-character (54\%). This MO is largely nonbonding with respect to the PDI ligand with minor Mo- $\mathrm{N}_{\mathrm{im}}\left(\sigma^{*}\right)$ contributions. This would account for these bonds being slightly longer in $[4]^{-}$ compared to 4 . Finally, the HOMO-1 for $[4]^{-}$is doubly-occupied and localized mostly on the PDI- $\pi^{*}$ system $(61 \%)$.

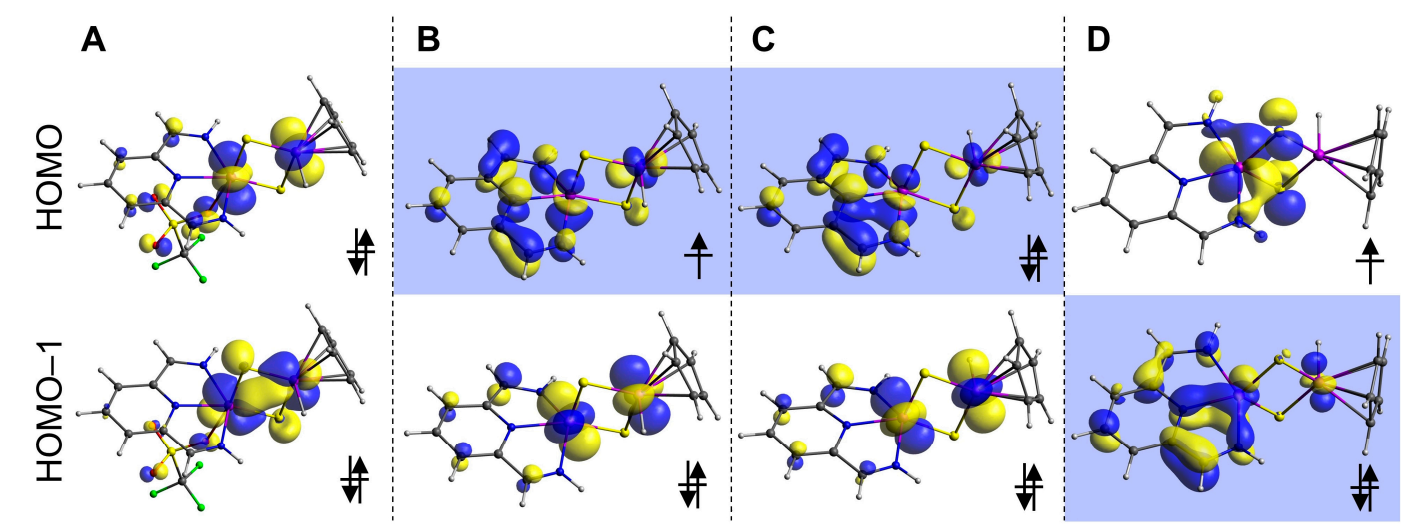

Figure 4. Selected unrestricted Kohn-Sham orbitals calculated for (A) $[4-\mathrm{OTf}]^{+},(\mathbf{B})[4]^{+},($C) 4 , and (D) $[4]^{-}$. Molecular orbitals with a shaded background have predominantly $\operatorname{PDI}\left(\pi^{*}\right)$ character.

\section{Discussion}

This work illustrates a new approach to the synthesis of bimetallic complexes featuring an $\mathrm{Mo}_{2} \mathrm{~S}_{2}$ core. Of note, protonation of 4 to give 5 was somewhat unexpected and warrants some comment. We had hypothesized that, given two-electron oxidation of 4 affords the isolable [4-OTf $]^{+}$, reaction of 4 with $\left[\mathrm{Ph}_{2} \mathrm{NH}_{2}\right]\left[\mathrm{BF}_{4}\right]$ would similarly give $\left[4-\mathrm{BF}_{4}\right]^{+}$via sequential two-electron steps; i.e., protonation of the Mo- $H$ atom followed by protonation of the $\mathrm{Cp}$-bound Mo. In contrast, $\mathrm{H}_{2}$ evolution from 4 to give 5 proceeds through, formally, one 2-electron and one single-electron step. In an effort to understand these processes, single equivalents of different anilinium acids were added to 4 . Although these reactions invariably gave mixtures, ${ }^{1} \mathrm{H}-\mathrm{NMR}$ analysis revealed that the major product was diamagnetic and still contained a $\mathrm{MoH}$ moiety. Importantly, a quartet at $\delta \sim 5.5(\mathrm{~J}=7 \mathrm{~Hz})$ of integration 1 relative to the $\mathrm{MoH}$ signal was consistently observed. We attribute this signal to the methine proton of a protonated imino carbon atom, with the hyperfine pattern due to coupling with the adjacent $\mathrm{CH}_{3}$ group. Addition of further protons to these mixtures gave 5 without discernable intermediate(s). We suggest the PDI-bound Mo in 4 is first protonated and that the resulting hydrido species rapidly transfers hydrogen to the imino-carbon[39,47]. How this complex is then protonated to give $\mathbf{5}$ is not clear, although bimolecular, homolytic $\mathrm{H}_{2}$ evolution from a MoH species seems likely. It is probable that similar ligand-protonation pathways give rise to the partially hydrogenated PDI observed in the cubane 6.

Taken together, the XRD and computational data presented herein permit formulation of Lewis structure representations for the four hydride complexes. These are shown in Figure 5. In summary, on moving from [4-OTf $]^{+}$to $[4]^{+}$to 4 the PDI ligand is formally reduced in one-electron steps from $\mathrm{PDI}^{0}$, to $\mathrm{PDI}^{\bullet-}$ to the dianion $\mathrm{PDI}^{2-}$. Further reduction to give $[4]^{-}$places an electron in an $\mathrm{MO}$ of mostly $\mathrm{Mo}(\mathrm{d})$-character with the PDI remaining as $\mathrm{PDI}^{2-}$. 


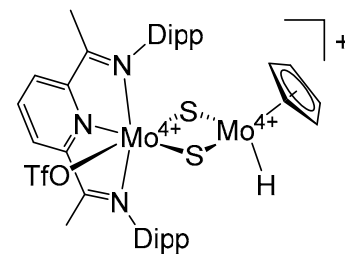

$[4-\mathrm{OTf}]^{+}$

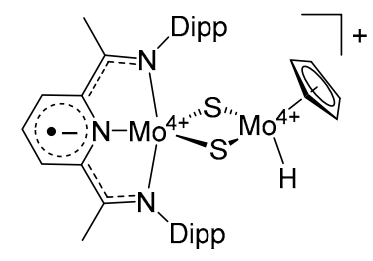

$[4]^{+}$

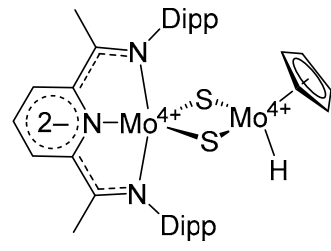

4

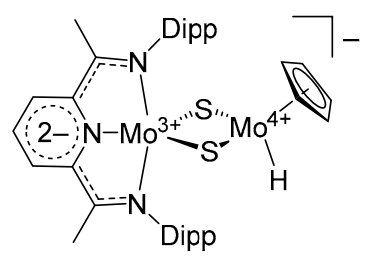

$[4]^{-}$

Figure 5. Assigned Lewis structures for the molybdenum-hydride complexes presented in this work.

\section{Conclusions}

A series of site-differentiated hydrido complexes featuring an $\mathrm{Mo}_{2} \mathrm{~S}_{2}$ core were prepared. These molecules represent rare examples of Mo-H complexes bound by sulfido ligands and are related to species proposed as intermediates in the HER catalyzed by MoS $x$ materials. Reactivity, XRD and computational studies showed that redox and protonation events for these complexes were mostly PDI-centered. This work further highlights the utility of PDI ligands as proton and electron-reservoirs. We are currently examining this class of complexes as electrocatalysts for proton reduction.

\section{Materials and Methods}

\subsection{Synthesis}

\subsubsection{General Considerations}

Unless stated otherwise, all compounds were purchased from commercial sources and used without further purification. Solvents were dried and deoxygenated by argon sparge followed by passage through an activated alumina column and were stored over $4 \AA$ molecular sieves. DBU was dried over $\mathrm{CaH}_{2}$ and distilled in vacuo. All Mo complexes, with the exception of (PDI) $\mathrm{MoCl}_{3}$, which could be handled in air for brief periods, were extremely air and moisture sensitive in solution and the solid state. As such, all manipulations were performed under an $\mathrm{N}_{2}$ atmosphere either in a glovebox or using standard Schlenk techniques. [ $\mathrm{MoCl}_{3}(\mathrm{THF})_{3}$ ] [48], (PDI) $\mathrm{MoCl}_{3}$ [39], PDI [49], $\mathrm{K}\left(\mathrm{C}_{10} \mathrm{H}_{8}\right)(\mathrm{THF})_{0.5}$ [50], $\mathrm{Cp}_{2} \mathrm{Mo}(\mathrm{SH})_{2}$ [40], [ $\left.\mathrm{Ph}_{3} \mathrm{C}\right]\left[\mathrm{BAr}_{4}{ }_{4}\right.$ ] [51], [ $\left.\mathrm{Fc}\right]\left[\mathrm{BAr}_{4}{ }_{4}\right.$ ] [52] and [Fc][OTf] [53] were synthesized according to literature procedures. $\left[\mathrm{Ph}_{2} \mathrm{NH}_{2}\right]\left[\mathrm{BF}_{4}\right]$ was prepared by addition of aqueous $\mathrm{H}\left[\mathrm{BF}_{4}\right]$ to a solution of $\mathrm{Ph}_{2} \mathrm{NH}$ in hexane and collecting the precipitate by filtration. NMR spectra were recorded at $298 \mathrm{~K}$ using Varian $300 \mathrm{MHz}, 400$ or $500 \mathrm{MHz}$ instruments. Chemical shifts were reported in ppm relative to tetramethylsilane using residual solvent as an internal standard. IR spectra were recorded using a PerkinElmer Spectrum One FT-IR spectrometer (Waltham, MA, USA) at $4 \mathrm{~cm}^{-1}$ resolution. EPR X-band spectra were recorded using a Bruker EMX spectrometer (Billerica, MA, USA) and analysed using Bruker Win-EPR software. Mass spectra were recorded using either an Agilent LCTOF mass spectrometer or a Waters GCT high resolution mass spectrometer operating in LIFDI mode. CV experiments were performed using a Pine AFP1 potentiostat. The cell consisted of a glassy carbon working electrode, a Pt wire auxiliary electrode and a Pt wire pseudo-reference electrode. All potentials were referenced vs. the $\mathrm{Fc}^{0 /+}$ couple measured as an internal standard. Elemental analyses were performed by Midwest Microlab. Solution-phase effective magnetic moments were determined by the method described by Evans [54] and corrected for diamagnetic contributions [55].

\subsubsection{Crystallography}

X-ray intensity data were collected on a Bruker APEX2 CCD detector (Billerica, MA, USA) employing graphite-monochromated Mo-K $\alpha$ radiation $(\lambda=0.71073 \AA)$ at $100(1) \mathrm{K}$. Absorption and other corrections were applied using SADABS [56]. The structures were solved by direct methods using SHELXT [57] and refined against $\mathrm{F}^{2}$ on all data by full-matrix least squares with SHELXL-2015 [58]. Nonhydrogen atoms were refined anisotropically. Hydrogen atoms bound to Mo were permitted 
to refine freely; all others were refined using a riding model. CCDC 2006498-2006504 contains the supplementary crystallographic data for this paper. These data can be obtained free of charge via http://www.ccdc.cam.ac.uk/conts/retrieving.html (or from the CCDC, 12 Union Road, Cambridge CB2 1EZ, UK; Fax: +44-1223-336033; E-mail: deposit@ccdc.cam.ac.uk).

\subsubsection{Experimental}

trans-(PDI) $\mathrm{MoCl}_{2}$ (THF) (1)

(PDI) $\mathrm{MoCl}_{3}(2.04 \mathrm{~g}, 2.98 \mathrm{mmol})$ and $\mathrm{K}\left(\mathrm{C}_{10} \mathrm{H}_{8}\right)(\mathrm{THF})_{0.5}(0.667 \mathrm{~g}, 3.28 \mathrm{mmol})$ were suspended in toluene $(20 \mathrm{~mL})$. After stirring for $3 \mathrm{~h}$ at RT the emerald green mixture was filtered through a pad of Celite. Dilution with 3 volumes of hexane and cooling at $-35{ }^{\circ} \mathrm{C}$ overnight produced pale green crystals which were collected by filtration. Recrystallisation by dissolving the complex in a minimum amount of THF and diluting with 3 volumes of hexane gave the product as glistening black-green crystals. Yield: $1.21 \mathrm{~g}, 56 \%$. Layering a saturated THF solution of the complex with hexane gave crystals suitable for XRD studies. ${ }^{1} \mathrm{H}$ NMR $\left(\mathrm{C}_{6} \mathrm{D}_{6}, 500 \mathrm{MHz}\right) \delta$ (br) 109.60, 77.50, 32.10, 8.93, 5.07, 4.34, $2.82,1.75,-8.42,-67.51$. Evans Method $\left(\mathrm{C}_{6} \mathrm{D}_{6}\right): \mu \mathrm{B} 2.7 \pm 0.2$.

trans-(PDI) $\mathrm{MoCl}_{2}(\mu-\mathrm{SH}) \mathrm{Mo}(\mathrm{SH}) \mathrm{Cp}_{2}$ (2)

$1(1.504 \mathrm{~g}, 2.09 \mathrm{mmol})$ and $\mathrm{Cp}_{2} \mathrm{Mo}(\mathrm{SH})_{2}(579 \mathrm{mg}, 1.98 \mathrm{mmol})$ were suspended in THF $(10 \mathrm{~mL})$. After stirring at RT for 30 min a purple microcrystalline solid separated from the mixture. Toluene $(20 \mathrm{~mL})$ was added to the suspension and the mixture cooled to $-35^{\circ} \mathrm{C}$ overnight to complete precipitation. The red-purple microcrystalline solid was collected by filtration and washed with toluene $(2 \times 5 \mathrm{~mL})$, twice with $\mathrm{Et}_{2} \mathrm{O}(2 \times 5 \mathrm{~mL})$ and dried under reduced pressure. Although not analytically pure, this material could be used in the next step without further purification. Yield: $1.640 \mathrm{~g}, \sim 88 \%$. 2 was soluble only in chlorinated solvents in which it decomposed over several hours. Nevertheless, layering a $\mathrm{CH}_{2} \mathrm{Cl}_{2}$ solution of the complex with hexane at $-35^{\circ} \mathrm{C}$ gave crystals of sufficient quality to assign bond connectivity by XRD studies. FT-IR: $\mathrm{cm}^{-1} 1875$ (SH).

$\left.(\mathrm{PDI}) \mathrm{Mo}(\mu-\mathrm{S}){ }_{2} \mathrm{Mo}\left(\eta^{5}-\mathrm{Cp}\right)\left(\eta^{1}-\mathrm{Cp}\right)\right](3)$

$2(950 \mathrm{mg}, 1.01 \mathrm{mmol})$ was suspended in toluene (10 mL). A solution of DBU (314 mg, $2.07 \mathrm{mmol})$ in toluene $(5 \mathrm{~mL})$ was added dropwise with rapid stirring. After stirring at RT for $30 \mathrm{~min}$ the dark-red mixture was diluted with an equal volume of hexane and filtered through a pad of celite. The solvent was removed under reduced pressure and the residue recrystallized by dissolving the solid in a minimum of THF, diluting with several volumes of $\mathrm{MeCN}$ and concentrating to $~ 50 \%$ of the original volume. The resulting black-red microcrystals were collected, washed with $\mathrm{MeCN}(3 \times 5 \mathrm{~mL})$ and dried under reduced pressure. Peaks for impurities were observed by ${ }^{1} \mathrm{H}$ NMR spectroscopy; however, this complex was sufficiently pure for the next step. Yield: $701 \mathrm{mg}, \sim 80 \%$. Layering a saturated THF solution of the complex with hexane gave crystals suitable for XRD studies. ${ }^{1} \mathrm{H}$ NMR $\left(\mathrm{C}_{6} \mathrm{D}_{6}\right.$, $400 \mathrm{MHz}) \delta 7.70(\mathrm{br}, 1 \mathrm{H}, \mathrm{pyH}), 7.37(\mathrm{br}, 1 \mathrm{H}, \mathrm{pyH}), 6.87(\mathrm{t}, J=7.6 \mathrm{~Hz}, 1 \mathrm{H}, \mathrm{pyH}), 6.18(\mathrm{br}, 2 \mathrm{H}, 2 \times \mathrm{DippH})$, $6.05(\mathrm{~d}, J=7.7 \mathrm{~Hz}, 4 \mathrm{H}, 4 \times \mathrm{DippH}), 4.18-4.97(\mathrm{~m}, \mathrm{br}, 10 \mathrm{H}, 10 \times \mathrm{CpH}), 2.42\left(\mathrm{br}, 2 \mathrm{H}, \mathrm{CH}(\mathrm{Me})_{2}\right), 2.18(\mathrm{br}, 2 \mathrm{H}$, $\left.\mathrm{CH}(\mathrm{Me})_{2}\right), 1.93\left(\mathrm{br}, 6 \mathrm{H}, 2 \times \mathrm{CH}_{3} \mathrm{C}=\mathrm{N}\right), 0.99\left(\mathrm{~d}, J=6.7 \mathrm{~Hz}, \mathrm{br}, 12 \mathrm{H}, 4 \times \mathrm{CH}_{3}\right), 0.48(\mathrm{~d}, J=6.7 \mathrm{~Hz}, \mathrm{br}, 12 \mathrm{H}$, $\left.4 \times \mathrm{CH}_{3}\right)$.

$(\mathrm{PDI}) \mathrm{Mo}(\mu-\mathrm{S}){ }_{2} \mathrm{Mo}\left(\eta^{5}-\mathrm{Cp}\right)(\mathrm{H})(4)$

To a mixture of $3(204 \mathrm{mg}, 0.235 \mathrm{mmol})$ and $\mathrm{Na}\left[\mathrm{BH}_{4}\right](100 \mathrm{mg}, 2.65 \mathrm{mmol})$ was added THF (5 mL) and the resulting mixture stirred at RT for $15 \mathrm{~min}$ to give a yellow-brown suspension. Prolonged reaction time gave decreased yields. The mixture was diluted with 2 volumes of hexane and filtered through a pad of Celite to remove excess $\mathrm{Na}\left[\mathrm{BH}_{4}\right]$. The solvent was removed under reduced pressure and the crude solid suspended in $\mathrm{Et}_{2} \mathrm{O}(5 \mathrm{~mL})$. A stir bar was added and the mixture stirred for $15 \mathrm{~min}$ before the black microcrystalline solid was collected by filtration and washed with $\mathrm{Et}_{2} \mathrm{O}(3 \times 5 \mathrm{~mL})$. 
Yield: $113 \mathrm{mg}, 60 \%$. 4-D was made analogously using $\mathrm{Na}\left[\mathrm{BD}_{4}\right](95 \% \mathrm{D})$. Recrystallization from THF-MeCN gave an analytical sample. Layering a saturated toluene solution of the complex with hexane gave crystals suitable for XRD studies. ${ }^{1} \mathrm{H}-\mathrm{NMR}\left(\mathrm{C}_{6} \mathrm{D}_{6}, 400 \mathrm{MHz}\right) \delta 7.71(\mathrm{~d}, J=7.5 \mathrm{~Hz}, 1 \mathrm{H}$, 3/5-pyH), 7.58 (d, $J=7.5 \mathrm{~Hz}, 1 \mathrm{H}, 3 / 5-\mathrm{pyH}), 6.84(\mathrm{t}, J=7.5 \mathrm{~Hz}, 1 \mathrm{H}, 4-\mathrm{pyH}), 6.58(\mathrm{t}, J=7.7 \mathrm{~Hz}, 1 \mathrm{H}$, 4-DippH), 6.49 (t, $J=7.7 \mathrm{~Hz}, 1 \mathrm{H}, 4-\mathrm{DippH}), 6.37(\mathrm{~d}, J=7.7 \mathrm{~Hz}, 2 \mathrm{H}, 2 \times 3,5-\mathrm{DippH}), 6.28(\mathrm{~d}, J=7.7 \mathrm{~Hz}$, 2H, $2 \times 3 / 5-\mathrm{DippH}), 5.54(\mathrm{~s}, 5 \mathrm{H}, 5 \times \mathrm{CpH}), 2.40$ (sept, $\left.J=6.7 \mathrm{~Hz}, 2 \mathrm{H}, 4 \times \mathrm{CH}(\mathrm{Me})_{2}\right), 2.07(\mathrm{~s}, 3 \mathrm{H}$, $\left.\mathrm{CH}_{3} \mathrm{C}=\mathrm{N}\right), 1.94\left(\mathrm{~s}, 3 \mathrm{H}, \mathrm{CH}_{3} \mathrm{C}=\mathrm{N}\right), 1.15\left(\mathrm{~d}, J=6.6 \mathrm{~Hz}, 6 \mathrm{H}, 2 \times \mathrm{CH}_{3}\right), 0.88\left(\mathrm{~d}, J=6.6 \mathrm{~Hz}, 6 \mathrm{H}, 2 \times \mathrm{CH}_{3}\right)$, $0.65\left(\mathrm{~d}, J=6.6 \mathrm{~Hz}, 6 \mathrm{H}, 2 \times \mathrm{CH}_{3}\right), 0.62\left(\mathrm{~d}, J=6.6 \mathrm{~Hz}, 6 \mathrm{H}, 2 \times \mathrm{CH}_{3}\right),-12.58(\mathrm{~s}, 1 \mathrm{H}, \mathrm{Mo}-\mathrm{H}) .{ }^{13} \mathrm{C}\left\{{ }^{1} \mathrm{H}\right\} \mathrm{NMR}$ $\left(\mathrm{C}_{6} \mathrm{D}_{6}, 101 \mathrm{MHz}\right) \delta 157.69,153.85,150.27,147.79,141.27,140.10,140.01,139.56,127.09,126.72,125.52$, 124.60, 123.29, 123.09, $118.60\left(13 \times \mathrm{ArC}+2 \times \mathrm{CH}_{3} \mathrm{C}=\mathrm{N}\right), 93.11(\mathrm{CpC}), 27.40,27.31\left(2 \times \mathrm{CH}(\mathrm{Me})_{2}\right), 25.28$, 25.09, 23.52, 23.49, 17.60, $17.08\left(6 \times \mathrm{CH}_{3}\right)$. FT-IR: $\mathrm{cm}^{-1}$ 3058, 2958, 2948, 2864, 1433, 1382, 1264, 1121, 959, 827, 759, 698, 637, 502. HR LIFDI MS(+): $m / z$ 807.1475; calc. for [4] ${ }^{+}: 807.1471$. Anal. calc. for $\mathrm{C}_{38} \mathrm{H}_{49} \mathrm{Mo}_{2} \mathrm{~N}_{3} \mathrm{~S}_{2}$ : C: 56.78; H: 6.14; N: 5.23. Found: C: 57.03; H: 6.35; N: 5.31.

$\left[(\mathrm{PDI}) \mathrm{Mo}(\mu-\mathrm{S})_{2} \mathrm{Mo}\left(\eta^{5}-\mathrm{Cp}\right)(\mathrm{H})\right][\mathrm{Na}($ crypt-222)] ([4][Na(crypt-222)])

$4(20.1 \mathrm{mg}, 0.0250 \mathrm{mmol})$ and freshly cut sodium (ca. $20 \mathrm{mg})$ were suspended in ether $(5 \mathrm{~mL})$. The mixture was stirred until no more solid 4 was visible $(\sim 1 \mathrm{~h})$. The dark orange-brown solution was filtered through a pad of Celite and a solution of 2.2.2-Cryptand $(10.3 \mathrm{mg}, 0.0274 \mathrm{mmol})$ in ether $(0.5 \mathrm{~mL})$ added. The resulting brown precipitate was collected by filtration. Recrystallization by dissolving this material in the minimum of THF and diluting with 3 volumes of ether gave the product as brown needles. Yield: $25 \mathrm{mg}, 84 \%$. Layering a saturated DMAc solution of the complex with toluene gave crystals suitable for XRD studies. ${ }^{1} \mathrm{H}-\mathrm{NMR}\left(\mathrm{d}_{7}-\mathrm{DMF}, 400 \mathrm{MHz}\right) \delta$ (br) 14.32, 13.25, 3.67 (cryptH), 3.63 (cryptH), 2.68 (cryptH), 2.11, 1.82, 1.26, -6.21. Evans Method (d $\mathrm{d}_{7}$-DMF): $\mu \mathrm{B}$ 1.9. FT-IR: $\mathrm{cm}^{-1}$ 3050, 2954, 2862, 1535, 1460, 1455, 1376, 1356, 1303, 1256, 1133, 1104, 955, 755. Anal. calc. for $\mathrm{C}_{56} \mathrm{H}_{85} \mathrm{Mo}_{2} \mathrm{~N}_{5} \mathrm{NaO}_{6} \mathrm{~S}_{2}$ : C: 55.89; H: 7.12; N: 5.82. Found: C: 56.05; H: 7.06; N: 5.99.

$\left[(\mathrm{PDI}) \mathrm{Mo}(\mu-\mathrm{S})_{2} \mathrm{Mo}\left(\eta^{5}-\mathrm{Cp}\right)(\mathrm{H})\right]\left[\mathrm{BAr}^{\mathrm{F}}{ }_{4}\right]\left([4]\left[\mathrm{BAr}^{\mathrm{F}}{ }_{4}\right]\right)$

A suspension of $\left[\mathrm{Ph}_{3} \mathrm{C}\right]\left[\mathrm{BAr}^{\mathrm{F}}{ }_{4}\right](45.0 \mathrm{mg}, 0.0407 \mathrm{mmol})$ in toluene $(2 \mathrm{~mL})$ was added slowly to a stirred solution of 4 ( $31.1 \mathrm{mg}, 0.0389 \mathrm{mmol})$ in toluene $(2 \mathrm{~mL})$. After stirring for several hours a dark blue microcrystalline solid precipitated which was collected by filtration and washed with toluene $(3 \times 5 \mathrm{~mL})$. The crude solid was recrystallized by dissolving in the minimum of $\mathrm{Et}_{2} \mathrm{O}$ and layering with 3 volumes of hexane to yield large blue prisms. Crystals suitable for XRD studies were obtained similarly. Yield: $45.4 \mathrm{mg}$, 70\%. ${ }^{1} \mathrm{H}-\mathrm{NMR}\left(\mathrm{d}_{8}-\mathrm{THF}, 500 \mathrm{MHz}\right) \delta(\mathrm{br}) 12.23,7.79\left(\mathrm{BAr}_{4}{ }_{4} \mathrm{H}\right), 7.57\left(\mathrm{BAr}_{4}{ }_{4} \mathrm{H}\right), 3.7,3.5,3.2$. Evans Method (d $\mathrm{d}_{8}$-THF): $\mu$ B $2.0 \pm$ 0.2. FT-IR: $\mathrm{cm}^{-1}$ 2970, 2934, 2875, 1611, 1646, 1386, 1356, 1278, 1164, $1129\left(\mathrm{CF}_{3}\right), 980$, 886, 839, 780, 715, 682, 670. HR LIFDI MS(+): $m / z$ 807.1477; calc. for [4] $]^{+}: 807.1471$. Anal. calc. for $\mathrm{C}_{70} \mathrm{H}_{61} \mathrm{BF}_{24} \mathrm{Mo}_{2} \mathrm{~N}_{3} \mathrm{~S}_{2} . \mathrm{C}_{6} \mathrm{H}_{14}$ : C: 52.06; H: 4.31; N: 2.40. Found: C: 51.98; H: 4.35; N: 2.24 .

[(PDI)Mo(OTf) $\left.(\mu-S){ }_{2} \mathrm{Mo}\left(\eta^{5}-\mathrm{Cp}\right)(\mathrm{H})\right][\mathrm{OTf}]([4-\mathrm{OTf}][\mathrm{OTf}])$

A suspension of [FC][OTf] $(18.7 \mathrm{mg}, 0.0558 \mathrm{mmol})$ in THF $(1 \mathrm{~mL}$ with an additional $2 \mathrm{~mL}$ for washing) was added slowly to a rapidly stirred solution of $4(22.4 \mathrm{mg}, 0.0279 \mathrm{mmol})$ in THF ( $1 \mathrm{~mL})$. The solution gradually changed from yellow-brown to blue then to orange-brown. The solution was filtered through Celite, concentrated to $\sim 0.5 \mathrm{~mL}$ and stored at $-35^{\circ} \mathrm{C}$ overnight, to produce shining red-black crystals of the complex. The supernatant was removed using a pipette and the solids washed with $\mathrm{Et}_{2} \mathrm{O}(3 \times 5 \mathrm{~mL})$. Yield: $(25.8 \mathrm{mg}, 84 \%)$. Recrystallization from acetone-ether at $-35{ }^{\circ} \mathrm{C}$ gave crystals suitable for XRD studies. ${ }^{1} \mathrm{H}$ NMR $\left(\mathrm{d}_{6}\right.$-acetone, $\left.400 \mathrm{MHz}\right) \delta 8.99(\mathrm{t}, J=8.0 \mathrm{~Hz}, 1 \mathrm{H}, 4$-pyH), $8.85(\mathrm{~d}, J=8.0 \mathrm{~Hz}, 1 \mathrm{H}, 3 / 5-\mathrm{pyH}), 8.80(\mathrm{~d}, J=8.0 \mathrm{~Hz}, 1 \mathrm{H}, 3,5-\mathrm{pyH}), 6.87(\mathrm{t}, J=7.7 \mathrm{~Hz}, 1 \mathrm{H}, 4-\mathrm{DippH})$, $6.83(\mathrm{t}, J=7.7 \mathrm{~Hz}, 1 \mathrm{H}, 4-\mathrm{DippH}), 6.67$ (m, br, 2H, 2 × 3/5-DippH), 6.61 (m, br, 1H, 3/5-DippH), 6.50 (m, br, 1H, 3/5-DippH), 6.19 (s, 5H, 5xCpH), $4.84\left(\mathrm{~m}, \mathrm{br}, 2 \mathrm{H}, 2 \times \mathrm{CH}(\mathrm{Me})_{2}\right), 3.28\left(\mathrm{~m}, \mathrm{br}, 2 \mathrm{H}, 2 \times \mathrm{CH}(\mathrm{Me})_{2}\right)$, $2.48\left(\mathrm{~s}, 3 \mathrm{H}, \mathrm{CH}_{3} \mathrm{C}=\mathrm{N}\right), 2.38\left(\mathrm{~s}, 3 \mathrm{H}, \mathrm{CH}_{3} \mathrm{C}=\mathrm{N}\right), 1.18\left(\mathrm{~m}, \mathrm{br}, 9 \mathrm{H}, 3 \times \mathrm{CH}_{3}\right), 0.83\left(\mathrm{~m}, \mathrm{br}, 6 \mathrm{H}, 2 \times \mathrm{CH}_{3}\right)$, $0.77\left(\mathrm{~m}, \mathrm{br}, 9 \mathrm{H}, 3 \times \mathrm{CH}_{3}\right),-12.02(\mathrm{~s}, \mathrm{br}, 1 \mathrm{H}, \mathrm{Mo}-\mathrm{H}) .{ }^{19} \mathrm{~F}\left\{{ }^{1} \mathrm{H}\right\} \mathrm{NMR}\left(\mathrm{d}_{6}\right.$-acetone, $\left.376 \mathrm{MHz}\right) \delta-78.85$ 
(br, $\mathrm{O}_{3} \mathrm{SCF}_{3}$ ). FT-IR: $\mathrm{cm}^{-1}$ 3089, 2970, 2930, 1872, 1435, 1386, 1319, 1280, 1276, 1231, 1207, 1180, 1156, 1031, 1019, 637, 519. HR LIFDI MS(+): $m / z$ 956.1039; calc. for [4-OTf]+: 956.0991. Anal. calc. for $\mathrm{C}_{40} \mathrm{H}_{49} \mathrm{~F}_{6} \mathrm{Mo}_{2} \mathrm{~N}_{3} \mathrm{O}_{6} \mathrm{~S}_{4}:$ C: $43.60 ; \mathrm{H}: 4.48 ; \mathrm{N}: 3.81$. Found: C: 43.45; H: 4.50; N: 3.99 .

$\left[(\mathrm{PDI}) \mathrm{Mo}(\mathrm{MeCN})(\mu-\mathrm{S})_{2} \mathrm{Mo}\left(\eta^{5-} \mathrm{Cp}\right)(\mathrm{MeCN})\right]\left[\mathrm{BF}_{4}\right]_{2}(5)$

$4(30.5 \mathrm{mg}, 0.0379 \mathrm{mmol})$ was suspended in $\mathrm{MeCN}(1 \mathrm{~mL})$ and a solution of $\left[\mathrm{Ph}_{2} \mathrm{NH}_{2}\right]\left[\mathrm{BF}_{4}\right]$ $(100 \mathrm{mg}, 0.389 \mathrm{mmol})$ in $\mathrm{MeCN}(1 \mathrm{~mL})$ added in one portion. The suspension rapidly cleared and vigorous gas evolution was observed. The dark purple solution was concentrated to near dryness and THF ( $3 \mathrm{~mL}$ ) added. Storage at $-35^{\circ} \mathrm{C}$ overnight gave dark black-purple blocks which were collected by filtration, washed with THF $(1 \mathrm{~mL})$ and then $\mathrm{Et}_{2} \mathrm{O}(3 \times 5 \mathrm{~mL})$. Yield $36.1 \mathrm{mg}, 90 \% .{ }^{1} \mathrm{H}-\mathrm{NMR}\left(\mathrm{d}_{3}-\mathrm{MeCN}\right.$, $400 \mathrm{MHz}$ ) $\delta$ (br) 25.90, 15.44, 15.04, 13.32, 11.19, 9.86, 9.51, 7.47, 6.11, 2.61, 2.50, 1.69, 1.05, 0.08, -1.53. Evans Method (d $\left.\mathrm{d}_{3}-\mathrm{MeCN}\right): \mu \mathrm{B} 2.0 \pm$ 0.1. FT-IR: $\mathrm{cm}^{-1}$ 3113, 2970, 2931, 1870, $2276(\mathrm{CN}), 2319(\mathrm{CN}), 1465$, 1433, 1386, 1276, 1058 (BF), 815, 781, 741, 521. Anal. calc. for $\mathrm{C}_{42} \mathrm{H}_{54} \mathrm{~B}_{2} \mathrm{~F}_{8} \mathrm{Mo}_{2} \mathrm{~N}_{5} \mathrm{~S}_{2}$ : C: 47.66; H: 5.14; N: 6.62. Found: C: 47.89; H: 5.25; N: 6.73.

Procedure for the Protonation of [4][Na(crypt-222)] to Give 6:

To a solution of [4][Na(crypt-222)] (10.0 mg, $0.0083 \mathrm{mmol})$ in $\mathrm{MeCN}(0.5 \mathrm{~mL})$ was added a solution of $\left[\mathrm{Ph}_{2} \mathrm{NH}_{2}\right]\left[\mathrm{BF}_{4}\right](11 \mathrm{mg}, 0.0043 \mathrm{mmol})$ in $\mathrm{MeCN}(0.5 \mathrm{~mL})$ which caused an immediate color change from brown-orange to pale orange. Addition of $\mathrm{Et}_{2} \mathrm{O}(\sim 3 \mathrm{~mL})$ caused immediate precipitation of a small amount of amorphous brown solid which was removed by filtration through a pad of Celite. Standing for several days at RT yielded a small amount of orange-red crystals surrounded by some amorphous brown solid. The supernatant was carefully decanted using a pipette and the crystals redissolved in $\mathrm{MeCN}(\sim 0.2 \mathrm{~mL})$. Layering this solution with $\mathrm{Et}_{2} \mathrm{O}$ gave small crystals of 6 suitable for XRD studies (see Figure S1E).

\subsection{DFT Calculations}

All calculations were carried out using version 4.1.2 of the ORCA program package [59] Coordinates for all non- $\mathrm{H}$ atoms were taken from the structures determined by $\mathrm{X}$-ray crystallography. To improve the efficiency of the calculations, the diisopropylphenyl and methyl groups of the PDI ligand were replaced by protons. All non-H atoms were fixed at their crystallographically-determined positions and the positions of all $\mathrm{H}$ atoms refined. Optimizations were performed using the Becke-Perdew GGA BP86 functional $[60,61]$ utilizing the Ahlrichs def2-TZVP [62-64] basis set for all atoms. Mo atoms were treated with a 28-electron small core pseudo-potential to account for relativistic effects [65]. The contracted auxiliary Coulomb fitting basis def2/J basis was applied to all atoms [66]. Grimme's atom-pairwise correction with Becke-Johnson damping (D3BJ) was included to account for the effects of dispersion[67]. No broken-symmetry solutions could be found for any of the molecules studied.

Supplementary Materials: The structures of 1, 2, 3, 5 and 6, selected spectroscopic data and lists of computed coordinates are available online.

Author Contributions: Conceptualization, A.M. and W.H.H.; formal analysis, J.W.T.; investigation, A.M.; project administration, W.H.H.; supervision, W.H.H.; writing—original draft, A.M.; writing—review \& editing, W.H.H. All authors have read and agreed to the published version of the manuscript.

Funding: This research was supported by the startup funds from the University of California, Riverside.

Acknowledgments: W.H.H. is a member of the University of California, Riverside Center for Catalysis. Fook Tham and Charlene Tsay are acknowledged for X-ray crystallographic analysis and Niklas B. Thompson for assistance with DFT calculations.

Conflicts of Interest: The authors declare no conflict of interest.

\section{References and Notes}

1. Turner, J.A. Sustainable Hydrogen Production. Science 2004, 305, 972-974. [CrossRef] [PubMed] 
2. Esswein, A.J.; Nocera, D.G. Hydrogen Production by Molecular Photocatalysis. Chem. Rev. 2007, 107, 4022-4047. [CrossRef] [PubMed]

3. Kudo, A.; Miseki, Y. Heterogeneous Photocatalyst Materials for Water Splitting. Chem. Soc. Rev. 2009, 38, 253-278. [CrossRef]

4. Jiao, Y.; Zheng, Y.; Jaroniec, M.T.; Qiao, S.Z. Design of Electrocatalysts for Oxygen- and Hydrogen-Involving Energy Conversion Reactions. Chem. Soc. Rev. 2015, 44, 2060-2086. [CrossRef] [PubMed]

5. Wang, Q.; Domen, K. Particulate Photocatalysts for Light-Driven Water Splitting: Mechanisms, Challenges, and Design Strategies. Chem. Rev. 2020, 120, 919-985. [CrossRef]

6. Abbas, H.F.; Daud, W.M.A.W. Hydrogen Production by Methane Decomposition: A Review. Int. J. Hydrogen Energy 2010, 35, 1160-1190. [CrossRef]

7. Holladay, J.D.; Hu, J.; King, D.L.; Wang, Y. An Overview of Hydrogen Production Technologies. Catal. Today 2009, 139, 244-260. [CrossRef]

8. Laursen, A.B.; Kegnaes, S.; Dahl, S.; Chorkendorff, I. Molybdenum Sulfides-Efficient and Viable Materials for Electro-and Photoelectrocatalytic Hydrogen Evolution. Energy. Environ. Sci. 2012, 5, 5577-5591. [CrossRef]

9. Yan, Y.; Xia, B.Y.; Xu, Z.C.; Wang, X. Recent Development of Molybdenum Sulfides as Advanced Electrocatalysts for Hydrogen Evolution Reaction. ACS Catal. 2014, 4, 1693-1705. [CrossRef]

10. Benck, J.D.; Hellstern, T.R.; Kibsgaard, J.; Chakthranont, P.; Jaramillo, T.F. Catalyzing the Hydrogen Evolution Reaction (HER) with Molybdenum Sulfide Nanomaterials. ACS Catal. 2014, 4, 3957-3971. [CrossRef]

11. Huang, Y.F.; Nielsen, R.J.; Goddard, W.A.; Soriaga, M.P. The Reaction Mechanism with Free Energy Barriers for Electrochemical Dihydrogen Evolution on $\mathrm{MoS}_{2}$. J. Am. Chem. Soc. 2015, 137, 6692-6698. [CrossRef] [PubMed]

12. Tran, P.D.; Tran, T.V.; Orio, M.; Torelli, S.; Truong, Q.D.; Nayuki, K.; Sasaki, Y.; Chiam, S.Y.; Yi, R.; Honma, I.; et al. Coordination Polymer Structure and Revisited Hydrogen Evolution Catalytic Mechanism for Amorphous Molybdenum Sulfide. Nat. Mater. 2016, 15, 640-646. [CrossRef] [PubMed]

13. Tang, Q.; Jiang, D.E. Mechanism of Hydrogen Evolution Reaction on $1 \mathrm{~T}-\mathrm{MoS}_{2}$ from First Principles. ACS Catal. 2016, 6, 4953-4961. [CrossRef]

14. Huang, Y.F.; Nielsen, R.J.; Goddard, W.A. Reaction Mechanism for the Hydrogen Evolution Reaction on the Basal Plane Sulfur Vacancy Site of $\mathrm{MoS}_{2}$ Using Grand Canonical Potential Kinetics. J. Am. Chem. Soc. 2018, 140, 16773-16782. [CrossRef]

15. Appel, A.M.; DuBois, D.L.; DuBois, M.R. Molybdenum-Sulfur Dimers as Electrocatalysts for the Production of Hydrogen at Low Overpotentials. J. Am. Chem. Soc. 2005, 127, 12717-12726. [CrossRef] [PubMed]

16. Karunadasa, H.I.; Montalvo, E.; Sun, Y.; Majda, M.; Long, J.R.; Chang, C.J. A Molecular MoS 2 Edge Site Mimic for Catalytic Hydrogen Generation. Science 2012, 335, 698-702. [CrossRef] [PubMed]

17. Eckenhoff, W.T.; Brennessel, W.W.; Eisenberg, R. Light-Driven Hydrogen Production from Aqueous Protons Using Molybdenum Catalysts. Inorg. Chem. 2014, 53, 9860-9869. [CrossRef] [PubMed]

18. Kibsgaard, J.; Jaramillo, T.F.; Besenbacher, F. Building an Appropriate Active-Site Motif into a Hydrogen-Evolution Catalyst with Thiomolybdate $\left[\mathrm{Mo}_{3} \mathrm{~S}_{13}\right]^{2-}$ Clusters. Nat. Chem. 2014, 6, 248-253. [CrossRef]

19. Garrett, B.R.; Click, K.A.; Durr, C.B.; Hadad, C.M.; Wu, Y.Y. $\left[\mathrm{MoO}\left(\mathrm{S}_{2}\right)_{2} \mathrm{~L}\right](1-)$ (L = picolinate or pyrimidine-2-carboxylate) Complexes as $\mathrm{MoS}_{\mathrm{x}}$-Inspired Electrocatalysts for Hydrogen Production in Aqueous Solution. J. Am. Chem. Soc. 2016, 138, 13726-13731. [CrossRef]

20. Garrett, B.R.; Polen, S.M.; Click, K.A.; He, M.F.; Huang, Z.J.; Hadad, C.M.; Wu, Y. Tunable Molecular MoS 2 Edge-Site Mimics for Catalytic Hydrogen Production. Inorg. Chem. 2016, 55, 3960-3966. [CrossRef]

21. Ji, Z.; Trickett, C.; Pei, X.K.; Yaghi, O.M. Linking Molybdenum-Sulfur Clusters for Electrocatalytic Hydrogen Evolution. J. Am. Chem. Soc. 2018, 140, 13618-13622. [CrossRef]

22. Rajagopal, A.; Venter, F.; Jacob, T.; Petermann, L.; Rau, S.; Tschierlei, S.; Streb, C. Homogeneous visible light-driven hydrogen evolution by the molecular molybdenum sulfide model $\left[\mathrm{Mo}_{2} \mathrm{~S}_{12}\right]^{2-}$. Sustain Energy Fuels 2019, 3, 92-95. [CrossRef]

23. Sellmann, D.; Zapf, L. Transition-Metal Complexes with Sulfur Ligands XIII*. Syntheses and Reactions of the 1,2-Benzenedithiolato Molybdate Complexes $\left[\mathrm{Mo}\left(\mathrm{C}_{6} \mathrm{H}_{4} \mathrm{~S}_{2}\right)_{3}\right]^{0},\left[\mathrm{Mo}\left(\mathrm{C}_{6} \mathrm{~S}_{4} \mathrm{~S}_{2}\right)_{3}\right]^{1-}$, $\left[\mathrm{Mo}\left(\mathrm{C}_{6} \mathrm{~S}_{4} \mathrm{~S}_{2}\right)_{3}\right]^{2-}$ and the Hydride Complex $\left[\mathrm{Mo}(\mathrm{H})\left(\mathrm{C}_{6} \mathrm{H}_{4} \mathrm{~S}_{2}\right)_{3}\right]^{3-}$. Z. Naturforsch. B 1985, 40, 380-388. [CrossRef]

24. Lazarowych, N.J.; Morris, R.H. Molybdenum Complexes Containing Hydride and Sulfur Donor Ligands. Synthesis and Properties of $\mathrm{Mo}(\mathrm{H})_{2}\left(\mathrm{~S}_{2} \mathrm{C}_{6} \mathrm{H}_{3} \mathrm{R}\right)\left(\mathrm{PMePh}_{2}\right)_{3}, \mathrm{Mo}(\mathrm{H})_{2}\left(\mathrm{~S}_{2} \mathrm{C}_{6} \mathrm{H}_{3} \mathrm{H}\right)\left(\mathrm{PMePh}_{2}\right)_{3}, \mathrm{R}=\mathrm{H}$, Me. J. Chem. Soc. Chem. Commun. 1987, 1865-1866. [CrossRef] 
25. Henderson, R.A.; Hughes, D.L.; Richards, R.L.; Shortman, C. The Preparation, Structure, and Reactions of the Mononuclear Thiolate-Hydride Complexes [MoH(SR)(Dppe)2] ( $\mathrm{R}=$ Bulky Alkyl or Aryl Group, Dppe $\left.=\mathrm{Ph}_{2} \mathrm{PCH}_{2} \mathrm{CH}_{2} \mathrm{PPh}_{2}\right)$-X-Ray Structure Determination of Cis-[MoH$\left.\left(\mathrm{SC}_{6} \mathrm{H}_{2} \mathrm{Pr}-2,4,6\right)(\mathrm{Dppe})_{2}\right]$. J. Chem. Soc. Dalton Trans. 1987, 1115-1121. [CrossRef]

26. Burrow, T.E.; Lazarowych, N.J.; Morris, R.H.; Lane, J.; Richards, R.L. Hydride Complexes of Molybdenum and Tungsten in a Sulfur Environment. Polyhedron 1989, 8, 1701-1704. [CrossRef]

27. Lu, S.F.; Huang, J.Q.; Zhuang, H.H.; Li, J.Q.; Wu, D.M.; Huang, Z.X.; Lu, C.Z.; Huang, J.L.; Lu, J.X. Synthesis, Structure and Molecular-Orbital Studies of a Series of Cubane-Type Tetranuclear Molybdenum (Tungsten) Clusters with $\left[\mathrm{S}_{2} \mathrm{P}\left(\mathrm{OC}_{2} \mathrm{H}_{5}\right)_{2}\right]_{-}$as Ligands. Polyhedron 1991, 10, 2203-2215.

28. Bernatis, P.; Haltiwanger, R.C.; Dubois, M.R. Sites of Electrophilic Attack in Neutral Dithiolate-Bridged Molybdenum Complexes. Organometallics 1992, 11, 2435-2443. [CrossRef]

29. Schollhammer, P.; Petillon, F.Y.; Pichon, R.; Poderguillou, S.; Talarmin, J.; Muir, K.W.; Girdwood, S.E. Reactions of Dinuclear and Polynuclear Complexes. 13. Synthesis, Structure and Fluxional Behavior of Hydrido-Bridged Thiolato-Bridged or Selenato-Bridged Complexes $\left[\mathrm{Mo}_{2} \mathrm{Cp}_{2}(\mu-\mathrm{H})(\mu-\mathrm{ER})(\mathrm{CO})_{4}\right](\mathrm{E}=\mathrm{S}$, $\mathrm{R}=\mathrm{Me}, \mathrm{tBu}, \mathrm{Bz}$, or Ph E = Se, R = Ph). J. Organomet. Chem. 1995, 486, 183-191. [CrossRef]

30. Hitchcock, P.B.; Hughes, D.L.; Maguire, M.J.; Marjani, K.; Richards, R.L. Disproportionation and reduction of hydrazine at a molybdenum-thiolate centre: Crystal structures of $\left[\mathrm{MoH}\left(\mathrm{SC}_{6} \mathrm{H}_{2} \mathrm{Pr}-2,4,6\right)_{3}\left(\mathrm{NH}_{3}\right)\left(\mathrm{PMePh}_{2}\right)\right]$ and $\left[\mathrm{MoH}\left(\mathrm{SC}_{6} \mathrm{H}_{2} \mathrm{Pr}-2,4,6\right)_{3}\left(\mathrm{NH}_{2} \mathrm{NHPh}\right)\left(\mathrm{PMePh}_{2}\right)\right]$. J. Chem. Soc. Dalton Trans. 1997, 4747-4752. [CrossRef]

31. Mathur, P.; Ghose, S.; Hossain, M.M.; Satyanarayana, C.V.V.; Drake, J.E. Synthesis and structural characterisation of a mixed Mo/Fe, mixed chalcogen, PhS-bridged cluster. J. Organomet. Chem. 1998, 557, 221-225. [CrossRef]

32. Takemoto, S.; Otsuka, K.; Otsuka, T.; Seino, H.; Mizobe, Y.; Hidai, M. Synthesis and structures of p-tert-butyltetrathiacalix[4]arene-dihydrides of $\mathrm{Mo}(\mathrm{V})$ and $\mathrm{W}(\mathrm{IV})$. Chem. Lett. 2002, 31, 6-7. [CrossRef]

33. Takemoto, S.; Tanaka, S.; Mizobe, Y.; Hidai, M. Ti-Mo Heterobimetallic Thiacalix[4]Arene Complex Containing an Unusual Alpha-Agostic $\mu-\eta^{5}: \eta^{2}$-Cyclopentadienyl Ligand. Chem. Commun. 2004, 838-839. [CrossRef] [PubMed]

34. Kajitani, H.; Seino, H.; Mizobe, Y. Synthesis of a Sulfido-Capped Trinuclear Cluster $\left[\left\{\left(\eta^{5}-\mathrm{C}_{5} \mathrm{Me}_{5}\right) \operatorname{Ir}\right\}_{2}\left\{\mathrm{Mo}(\mathrm{CO})_{3}\right\}\right.$ $\left.\left(\mu_{3}-S\right)_{2}\right]$ and its Reactions at the Molybdenum Site Forming a Series of $\operatorname{Ir}_{2} \mathrm{MoS}_{2}$ clusters. Organometallics 2007, 26, 3499-3508. [CrossRef]

35. Buccella, D.; Parkin, G. Mononuclear and Dinuclear Molybdenum and Tungsten Complexes of p-tert-butyltetrathiacalix[4]arene and p-tert-butyltetrasulfonylcalix[4]arene: Facile cleavage of the calixarene ligand framework by nickel. J. Am. Chem. Soc. 2008, 130, 8617-8619. [CrossRef] [PubMed]

36. Algarra, A.G.; Basallote, M.G.; Fernandez-Trujillo, M.J.; Feliz, M.; Guillamon, E.; Llusar, R.; Sorribes, I.; Vicent, C. Chiral $\left.\left[\mathrm{Mo}_{3} \mathrm{~S}_{4} \mathrm{H}_{3} \text { (diphosphine) }\right)_{3}\right]^{+}$Hydrido Clusters and Study of the Effect of the Metal Atom on the Kinetics of the Acid-Assisted Substitution of the Coordinated Hydride: Mo vs. W. Inorg. Chem. 2010, 49, 5935-5942. [CrossRef]

37. Sattler, A.; Janak, K.E.; Parkin, G. Modeling Aspects of Hydrodesulfurization by Molybdenum Hydride Compounds: Desulfurization of Thiophene and Benzothiophene and C-S Bond Cleavage of Dibenzothiophene. Inorg. Chim. Acta 2011, 369, 197-202. [CrossRef]

38. >300 structures on the CCDC as of 2020.

39. Margulieux, G.W.; Turner, Z.R.; Chirik, P.J. Synthesis and Ligand Modification Chemistry of a Molybdenum Dinitrogen Complex: Redox and Chemical Activity of a Bis(imino)Pyridine Ligand. Angew. Chem. Int. Ed. 2014, 53, 14211-14215. [CrossRef]

40. Green, M.L.H.; Lindsell, W.E. Some Bis- $\pi$-Cyclopentadienyl-Molybdenum and-Tungsten Complexes with Sulphur or Oxygen Ligands. J. Chem. Soc. A 1967, 1455-1457. [CrossRef]

41. Kaesz, H.D.; Saillant, R.B. Hydride Complexes of the Transition-Metals. Chem. Rev. 1972, 72, 231-281. [CrossRef]

42. Silavwe, N.D.; Castellani, M.P.; Tyler, D.R.; Beck, M.A.; Lichtenhan, J.D.; Doherty, N.M. Inorganic Syntheses; John Wiley \& Sons, Inc.: Charlottesuille, VA, USA, 1992; Chapter 4, pp. $204-211$.

43. Scarborough, C.C.; Lancaster, K.M.; DeBeer, S.; Weyhermueller, T.; Sproules, S.; Wieghardt, K. Experimental Fingerprints for Redox-Active Terpyridine in $\left[\mathrm{Cr}(\operatorname{tpy})_{2}\right]\left(\mathrm{PF}_{6}\right)(\mathrm{N})(\mathrm{N}=3-0)$, and the Remarkable Electronic Structure of $\left[\mathrm{Cr}(\mathrm{tpy})_{2}\right]^{1-}$. Inorg. Chem. 2012, 51, 3718-3732. [CrossRef]

44. de Bruin, B.; Bill, E.; Bothe, E.; Weyhermuller, T.; Wieghardt, K. Molecular and electronic structures of bis(pyridine-2,6-diimine)metal complexes $\left[\mathrm{ML}_{2}\right]\left(\mathrm{PF}_{6}\right)^{\mathrm{n}}(\mathrm{n}=0,1,2,3 ; \mathrm{M}=\mathrm{Mn}, \mathrm{Fe}, \mathrm{Co}, \mathrm{Ni}, \mathrm{Cu}, \mathrm{Zn})$. Inorg. Chem. 2000, 39, 2936-2947. [CrossRef] [PubMed]

45. Luca, O.R.; Crabtree, R.H. Redox-Active Ligands in Catalysis. Chem. Soc. Rev. 2013, 42, 1440-1459. [CrossRef] 
46. Knijnenburg, Q.; Gambarotta, S.; Budzelaar, P.H.M. Ligand-Centred Reactivity in Diiminepyridine Complexes. Dalton Trans. 2006, 5442-5448. [CrossRef] [PubMed]

47. Margulieux, G.W.; Bezdek, M.J.; Turner, Z.R.; Chirik, P.J. Ammonia Activation, $\mathrm{H}_{2}$ Evolution and Nitride Formation from a Molybdenum Complex with a Chemically and Redox Noninnocent Ligand. J. Am. Chem. Soc. 2017, 139, 6110-6113. [CrossRef] [PubMed]

48. Stoffelbach, F.; Saurenz, D.; Poli, R. Improved Preparations of Molybdenum Coordination Compounds from Tetrachlorobis(diethyl Ether)Molybdenum(IV). Eur. J. Inorg. Chem. 2001, 2699-2703. [CrossRef]

49. Greenhalgh, M.D.; Thomas, S.P. Iron-Catalyzed, Highly Regioselective Synthesis of Alpha-Aryl Carboxylic Acids from Styrene Derivatives and $\mathrm{CO}_{2}$. J. Am. Chem. Soc. 2012, 134, 11900-11903. [CrossRef]

50. Scott, T.A.; Ooro, B.A.; Collins, D.J.; Shatruk, M.; Yakovenko, A.; Dunbar, K.R.; Zhou, H.C. After 118 Years, the Isolation of Two Common Radical Anion Reductants as Simple, Stable Solids. Chem. Commun. 2009, 65-67. [CrossRef]

51. Bahr, S.R.; Boudjouk, P. Trityl Tetrakis(3,5-Bis(Trifluoromethyl)Phenyl)Borate-A New Hydride Abstraction Reagent. J. Org. Chem. 1992, 57, 5545-5547. [CrossRef]

52. Le Bras, J.; Jiao, H.J.; Meyer, W.E.; Hampel, F.; Gladysz, J.A. Synthesis, crystal structure, and reactions of the 17-valence-electron rhenium methyl complex $\left.\left[\left(\eta^{5}-\mathrm{C}_{5} \mathrm{Me}\right)_{5}\right) \operatorname{Re}(\mathrm{NO})\left(\mathrm{P}\left(4-\mathrm{C}_{6} \mathrm{H}_{4} \mathrm{CH}_{3}\right)_{3}\right)\left(\mathrm{CH}_{3}\right)\right]^{+}$ $\mathrm{B}\left(3,5-\mathrm{C}_{6} \mathrm{H}_{3}\left(\mathrm{CF}_{3}\right)_{2}\right)_{4}^{-}$: Experimental and computational bonding comparisons with 18-electron methyl and methylidene complexes. J. Organomet. Chem. 2000, 616, 54-66. [CrossRef]

53. Li, Z.W.; Yeh, A.; Taube, H. Mixed-Valence Molecules Based on Monohydridobis(Ethylenediamine) Osmium(IV) and Metal Cyano Complexes. Inorg. Chem. 1994, 33, 2874-2881. [CrossRef]

54. Schubert, E.M. Utilizing the Evans Method with a Superconducting NMR Spectrometer in the Undergraduate Laboratory. J. Chem. Educ. 1992, 69, 62. [CrossRef]

55. Bain, G.A.; Berry, J.F. Diamagnetic Corrections and Pascal's Constants. J. Chem. Educ. 2008, 85, 532-536. [CrossRef]

56. SADABS; Version 2014/5; Bruker AXS Inc.: Madison, WI, USA, 2001.

57. Sheldrick, G.M. Shelxt-Integrated Space-Group and Crystal-Structure Determination. Acta Cryst. A 2015, 71, 3-8. [CrossRef] [PubMed]

58. Sheldrick, G.M. Crystal Structure Refinement with ShelXL. Acta Cryst. C 2015, 71, 3-8. [CrossRef]

59. Neese, F. The Orca Program System. Wires Comput. Mol. Sci. 2012, 2, 73-78. [CrossRef]

60. Lee, C.T.; Yang, W.T.; Parr, R.G. Development of the Colle-Salvetti Correlation-Energy Formula into a Functional of the Electron-Density. Phys. Rev. B 1988, 37, 785-789. [CrossRef]

61. Becke, A.D. Density-Functional Thermochemistry. 3. The Role of Exact Exchange. J. Chem. Phys. 1993, 98, 5648-5652. [CrossRef]

62. Schafer, A.; Horn, H.; Ahlrichs, R. Fully Optimized Contracted Gaussian-Basis Sets for Atoms Li to Kr. J. Chem. Phys. 1992, 97, 2571-2577. [CrossRef]

63. Schafer, A.; Huber, C.; Ahlrichs, R. Fully Optimized Contracted Gaussian-Basis Sets of Triple Zeta Valence Quality for Atoms Li to Kr. J. Chem. Phys. 1994, 100, 5829-5835. [CrossRef]

64. Weigend, F.; Ahlrichs, R. Balanced Basis Sets of Split Valence, Triple Zeta Valence and Quadruple Zeta Valence Quality for H to Rn: Design and Assessment of Accuracy. Phys. Chem. Chem. Phys. 2005, 7, 3297-3305. [CrossRef] [PubMed]

65. Andrae, D.; Haussermann, U.; Dolg, M.; Stoll, H.; Preuss, H. Energy-Adjusted Ab initio Pseudopotentials for the 2nd and 3rd Row Transition-Elements. Theor. Chim. Acta 1990, 77, 123-141. [CrossRef]

66. Weigend, F. Accurate Coulomb-Fitting Basis Sets for H to Rn. Phys. Chem. Chem. Phys. 2006, 8, 1057-1065. [CrossRef] [PubMed]

67. Grimme, S.; Antony, J.; Ehrlich, S.; Krieg, H. A Consistent and Accurate Ab Initio Parametrization of Density Functional Dispersion Correction (DFT-D) for the 94 Elements H-Pu. J. Chem. Phys. 2010, 132, 15104-15119. [CrossRef] [PubMed]

Sample Availability: Samples of the compounds are not available from the authors.

(C) 2020 by the authors. Licensee MDPI, Basel, Switzerland. This article is an open access article distributed under the terms and conditions of the Creative Commons Attribution (CC BY) license (http://creativecommons.org/licenses/by/4.0/). 